\title{
Deep brain stimulation for Parkinson's disease: defining the optimal location within the subthalamic nucleus
}

\author{
Maarten Bot, ${ }^{1}$ P Richard Schuurman, ${ }^{1}$ Vincent J J Odekerken, ${ }^{2}$ Rens Verhagen, ${ }^{1,2}$ \\ Fiorella Maria Contarino, ${ }^{2,3,4}$ Rob M A De Bie, ${ }^{2}$ Pepijn van den Munckhof ${ }^{1}$
}

\begin{abstract}
${ }^{1}$ Department of Neurosurgery, Academic Medical Center, Amsterdam, The Netherlands ${ }^{2}$ Department of Neurology and Clinical Neurophysiology, Academic Medical Center, Amsterdam, The Netherlands ${ }^{3}$ Department of Neurology, Leiden University Medical Center, Leiden, The Netherlands ${ }^{4}$ Department of Neurology, Haga Teaching Hospital, Den Haag, The Netherlands
\end{abstract}

Correspondence to Dr Maarten Bot, Department of Neurosurgery, Academic Medical Center, Meibergdreef 9, 1105 AZ Amsterdam, The Netherlands; m.bot@amc.nl

Received 19 July 2017 Revised 12 November 2017 Accepted 20 November 2017

\section{Check for updates}

\section{To cite: Bot $M$,}

Schuurman PR,

Odekerken VJJ, et al. J Neurol

Neurosurg Psychiatry Epub

ahead of print: [please

include Day Month Year].

doi:10.1136/jnnp-2017-

316907

\section{ABSTRACT}

Background Individual motor improvement after deep brain stimulation (DBS) of the subthalamic nucleus (STN) for Parkinson's disease (PD) varies considerably. Stereotactic targeting of the dorsolateral sensorimotor part of the STN is considered paramount for maximising effectiveness, but studies employing the midcommissural point (MCP) as anatomical reference failed to show correlation between DBS location and motor improvement. The medial border of the STN as reference may provide better insight in the relationship between DBS location and clinical outcome.

Methods Motor improvement after 12 months of 65 STN DBS electrodes was categorised into nonresponding, responding and optimally responding body-sides. Stereotactic coordinates of optimal electrode contacts relative to both medial STN border and MCP served to define theoretic DBS 'hotspots'.

Results Using the medial STN border as reference, significant negative correlation (Pearson's correlation $-0.52, P<0.01$ ) was found between the Euclidean distance from the centre of stimulation to this DBS hotspot and motor improvement. This hotspot was located at $2.8 \mathrm{~mm}$ lateral, $1.7 \mathrm{~mm}$ anterior and $2.5 \mathrm{~mm}$ superior relative to the medial STN border. Using MCP as reference, no correlation was found.

Conclusion The medial STN border proved superior compared with MCP as anatomical reference for correlation of DBS location and motor improvement, and enabled defining an optimal DBS location within the nucleus. We therefore propose the medial STN border as a better individual reference point than the currently used MCP on preoperative stereotactic imaging, in order to obtain optimal and thus less variable motor improvement for individual patients with PD following STN DBS.

\section{INTRODUCTION}

Deep brain stimulation (DBS) of the subthalamic nucleus (STN) is the most effective surgical treatment for patients with advanced Parkinson's disease (PD). Precise stereotactic targeting of the dorsolateral sensorimotor part of the STN is considered paramount for maximising clinical effectiveness. In centres specialised in STN DBS for PD, improvement of off-drug phase Unified Parkinson's Disease Rating Scale (UPDRS) motor scores after 12 months of DBS averages 46\%-66\%. ${ }^{1-5}$ Individual outcome after DBS surgery, however, varies considerably with UPDRS motor score changes ranging from $57 \%$ deterioration to $92 \%$ improvement. ${ }^{6}$ Location of DBS electrodes relative to the dorsolateral sensorimotor part of the STN may, in part, explain the large range in clinical outcome. Since this part of the STN cannot readily be identified on MRI, the neuroanatomical location of electrode contacts on postoperative imaging is usually expressed as stereotactic distances relative to the anterior and posterior commissural (AC-PC) plane and midcommissural point (MCP). Thus far, stereotactic distances of active electrode contacts relative to MCP showed no significant correlation for individual motor outcome after DBS surgery, ${ }^{7-12}$ leading some to doubt the relationship between the neuroanatomical location of electrode contacts and clinical effectiveness of DBS. ${ }^{7314}$ An alternative explanation, however, could be that the use of MCP as reference may not take individual anatomical variation of STN location relative to MCP into account. We therefore decided to use the medial border of the STN, easily identifiable on MRI, as individual reference for evaluating the relationship between active contact location and clinical outcome in order to gain better insight in the optimal location of DBS for PD.

\section{METHODS}

Patients

Patients were selected from a multicentre randomised controlled study on the effectiveness of STN versus globus pallidus internus DBS that included patients between February 2007 and March 2011. Patients were considered for current analysis when they underwent STN DBS surgery at our institution, and when postoperative CT and unilateral UPDRS motor examination scores 12 months after surgery were available.

\section{Surgical procedure and localisation of electrode contacts}

On the day of surgery, the Leksell stereotactic $G$ frame (Elekta Instrument AB, Stockholm, Sweden) was placed and patients underwent a $1.5 \mathrm{~T}$ stereotactic MRI (Siemens, Malvern, Pennsylvania, USA) with axial T2-weighted and postgadolinium (Gd) volumetric axial T1-weighted sequences. STN target planning was started using standard stereotactic coordinates calculated from MCP: $12 \mathrm{~mm}$ in lateral direction, $2 \mathrm{~mm}$ in posterior direction, 
$4 \mathrm{~mm}$ in ventral direction. Target planning was subsequently optimised based on red nucleus (RN) and STN visualisation on T2 sequences. Trajectory planning was done using post-Gd volumetric T1-weighted sequence. Entry points were chosen precoronal and $3-4 \mathrm{~cm}$ lateral from the midline on a suitable gyrus. Planned trajectories were inspected to avoid penetration of ventricles and blood vessels. Planning was done using SurgiPlan (Elekta Instrument). All patients were operated under local anaesthetics with the head-frame secured to the operating table. Patients were placed in supine position with the head elevated $20^{\circ}$ to $30^{\circ}$ to minimise outflow of cerebrospinal fluid. Surgery started contralateral to the most affected side. Microelectrode recordings (MER) were performed using one to five parallel tracks. After the optimal track was determined, a quadripolar DBS electrode with contact points $1.5 \mathrm{~mm}$ long and separated from adjacent contacts by $0.5 \mathrm{~mm}$ (model 3389, Medtronic, Minneapolis, Minnesota, USA) was implanted under fluoroscopic guidance and secured to the skull using Stimlock system (Medtronic). Subsequent implantation of one or two pulse generators was done in a subcutaneous or subpectoral pocket in the infraclavicular region under general anaesthesia on the same day.

After 1 year, a CT scan (Philips Medical System, Best, The Netherlands) was performed and coregistered to the stereotactic MRI using SurgiPlan, in order to determine the position of the electrode contact point used for active stimulation at the time of the UPDRS motor score assessment. To determine this position relative to the electrophysiological STN, the Z-(dorsoventral) distance was measured between the electrophysiological dorsal STN border in the microelectrode track used for final electrode implantation and the centre of the active contact point.

In general, one contact point (monopolar stimulation) was activated; when two contact points were activated simultaneously (bipolar or double monopolar stimulation), the interspace between active contact points was chosen as centre of stimulation.

\section{Electrode contact localisation relative to medial STN border}

Measurements were done using 1.5 T T2-weighted MRI with SurgiPlan. First, the maximum diameter of the RN in axial-orientated T2-weighted MRI was determined using both axial and coronal orientated AC-PC aligned T2-weighted MRI. Subsequently, a line perpendicular to the AC-PC line was drawn coinciding with the anterior border of the $\mathrm{RN}$ along its trajectory (Bejjani line). ${ }^{15}$ The point of intersection with the medial STN border (medial border of hypointense crescent area lateral to $\mathrm{RN}$ ) was then determined and stereotactic coordinates relative to MCP were noted (figure 1). This was separately done for left and right mesencephalic area. The stereotactic X-(lateral), Y-(anteroposterior) and Z-(dorsoventral) distances of the centre of the contact point of active stimulation relative to the medial STN border and MCP were determined on postoperative CT coregistered to stereotactic T1-weighted MRI.

\section{Correlation between motor score improvement and location of DBS}

UPDRS motor score assessment was performed at baseline and 12 months after surgery. Standardised assessments were done during off-drug and on-drug phase, 12-month assessment was done with the stimulator turned on. Left-sided and rightsided motor scores (UPDRS part III items 3.3-3.8) were separately evaluated, axial motor scores were not included in the current analysis. ${ }^{16}$ Improvement in UPDRS motor score between off-drug/on-stimulation after 12 months and baseline off-drug was used to categorise contralateral body-sides into three groups: (1) non-responding (<30\%), (2) responding (between 30\% and $70 \%)$ and (3) optimally responding (>70\%).

The average $\mathrm{X}, \mathrm{Y}$ and $\mathrm{Z}$ distance from centre of stimulation of optimally responding contralateral body-sides to the medial STN border and MCP were used to calculate two different theoretic optimal DBS locations ('hotspots'), one relative to the medial STN border and one relative to MCP. Subsequently, for each individual contralateral body-side the Euclidean distance $\left(\sqrt{(\Delta \mathrm{X})^{2}+(\Delta \mathrm{Y})^{2}+(\Delta \mathrm{Z})^{2}}\right)$ from the centre of stimulation to the hotspot relative to the medial STN border and to the hotspot relative to MCP was calculated.

Improvement of unilateral UPDRS motor scores for centres of stimulation was subsequently integrated into plots: (1) box plot showing Euclidean distance from centre of stimulation of non-responding, responding and optimally responding body-sides to the theoretic optimal DBS location ('hotspot'), both relative to medial STN border and relative to MCP; (2) scatter plot showing percentage unilateral UPDRS improvement and Euclidean distance from centres of stimulation of individual body-sides to the theoretic hotspot, both relative to medial STN border and relative to MCP.

Numerical data are presented as mean $\pm S D$ after testing for normal distribution using the Shapiro-Wilk test. Group comparison was performed using independent samples t-tests. Strength of association was evaluated using Pearson's correlation. In all statistical analysis, differences were considered significant if $\mathrm{P}<0.05$.
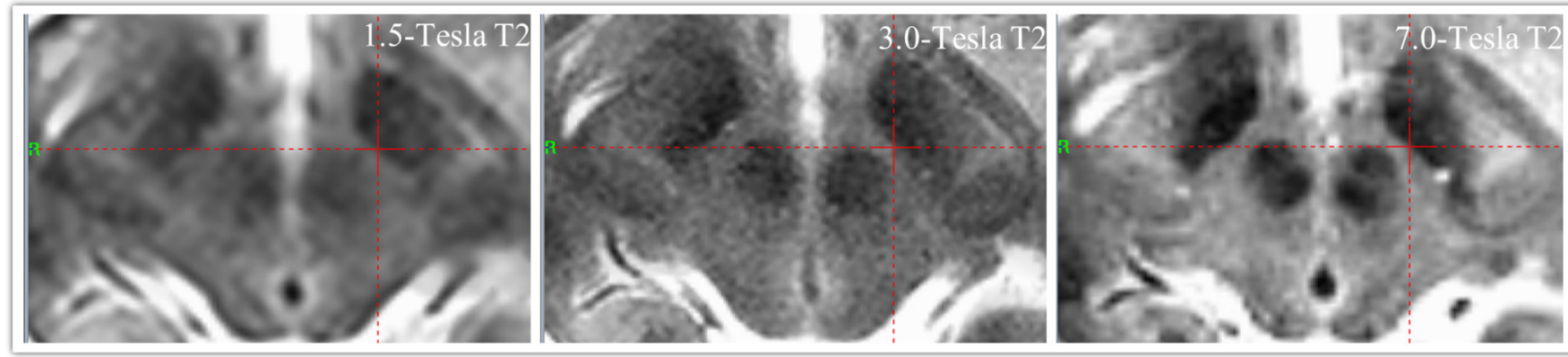

Figure 1 Axial midbrain section showing medial subthalamic nucleus (STN) border at maximal diameter of red nucleus (RN) on three different MRI sequences. Left, a 1.5 T T2 sequence; middle, a 3.0 T T2 sequence; and right, a 7.0 T T2 sequence. The hypointense STN signal is situated anterolateral to the RN. The cross-section of the two dotted red lines coincides with the medial STN border reference point. In the current study, only $1.5 \mathrm{~T}$ was applied (left panel), but identification of medial STN border can also be readily applied on 3.0 T (middle) and 7.0 T field strengths. 


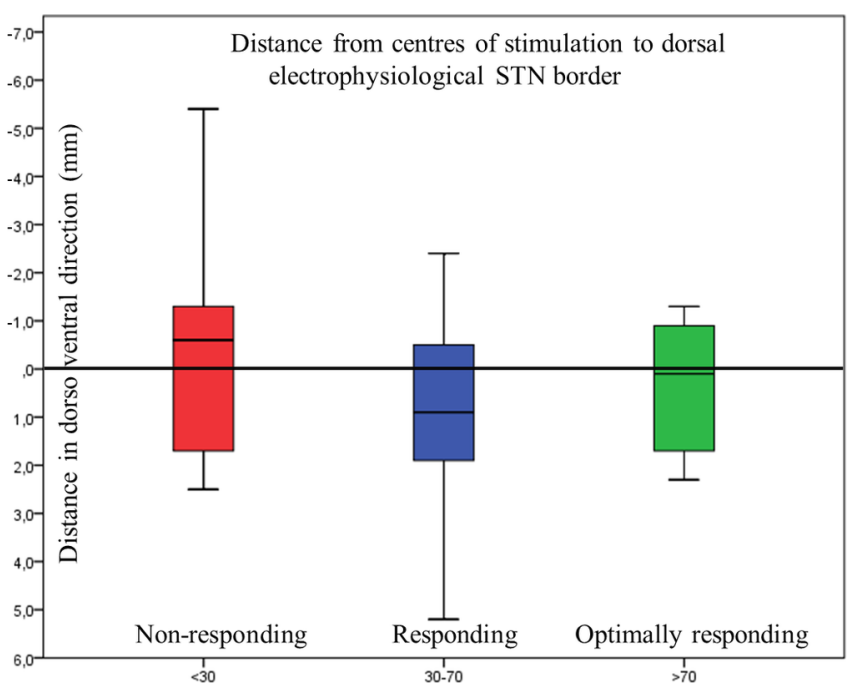

Figure 2 Distance in dorsoventral direction (Z-distance) from centres of stimulation of non-responding ( $<30 \%$ Unified Parkinson's Disease Rating Scale motor improvement after 12 months, red box plot), responding (30\%-70\% improvement, blue box plot) and optimally responding (>70\% improvement, green box plot) group relative to dorsal electrophysiological subthalamic nucleus (STN) border as defined by microelectrode recordings. Average distances did not differ between groups and active contact points were in close proximity to the electrophysiological dorsal STN border for all three groups.

\section{RESULTS}

A total of 80 DBS electrodes were placed in 40 patients with PD. There were 32 male and 8 female patients and average age at surgery was $62 \pm 6$ years. Average disease duration was $11 \pm 7$ years. All patients underwent bilateral DBS placement. In three patients the 12-month postoperative CT was not available, in one patient the 12-month postoperative UPDRS score was not available, in two patients the 12-month electrode contact used for stimulation was not available, in one patient T2-weighted MRI image quality was insufficient for medial STN border identification, one patient underwent repositioning of one DBS electrode. Therefore, a total of 65 DBS electrodes (33 patients) were used for the current analysis. There were 17 non-responding body-sides, 30 responding body-sides and 18 optimally responding body-sides. Baseline levodopa response for non-responding, responding and optimally responding body-sides was, $63 \%, 65 \%$ and $72 \%$, respectively. Stimulation was at $60 \mu \mathrm{s}$ and $130 \mathrm{~Hz}$, with current for non-responding, responding and optimally responding body-sides averaging, respectively, 2.4, 2.5 and $2.5 \mathrm{~mA}$. Monopolar stimulation was applied for 59 body-sides (91\%). For all three groups, contact points of active stimulation were in close proximity to the electrophysiological dorsal STN border, with distances for non-responding, responding and optimally responding groups averaging $0.3 \pm 2.1,0.9 \pm 1.9,0.3 \pm 1.3$ $\mathrm{mm}$ (figure 2). Unilateral off-drug phase UPDRS motor score for responding and optimally responding body-sides showed an average improvement of, respectively, 57\% and 85\%. For non-responding body-sides an average of $6 \%$ deterioration was seen.

\section{Medial STN border and MCP evaluation}

Mean stereotactic coordinates of the intersection of Bejjani's line with the medial STN border relative to MCP were quite variable, at 9.2 \pm 1.1 (range 6.8-11.5) mm lateral, $2.8 \pm 0.8$ (range 1.5-5.3) $\mathrm{mm}$ posterior and $4.2 \pm 1.0$ (range 2.0-6.1) $\mathrm{mm}$ inferior.
Table 1

\begin{tabular}{|c|c|c|c|c|c|c|}
\hline & \multicolumn{3}{|c|}{ Medial STN border } & \multicolumn{3}{|c|}{ Midcommissural point } \\
\hline & Lateral & Anterior & Superior & Lateral & Posterior & Inferior \\
\hline $\begin{array}{l}\text { Non- } \\
\text { responding }\end{array}$ & $2.5 \pm 1.1$ & $1.6 \pm 2.4$ & $1.1 \pm 2.0$ & $11.7 \pm 1.5$ & $0.9 \pm 1.9$ & $2.7 \pm 1.8$ \\
\hline Responding & $3.0 \pm 1.2$ & $1.6 \pm 1.3$ & $1.0 \pm 1.4$ & $12.1 \pm 1.6$ & $1.2 \pm 1.1$ & $3.0 \pm 1.6$ \\
\hline $\begin{array}{l}\text { Optimally } \\
\text { responding }\end{array}$ & $2.8 \pm 1.3$ & $1.7 \pm 1.5$ & $2.5 \pm 1.4^{*}$ & $12.3 \pm 1.2$ & $1.6 \pm 1.4$ & $2.3 \pm 1.6$ \\
\hline \multicolumn{7}{|c|}{$\begin{array}{l}\text { Mean stereotactic distances from centres of stimulation of non-responding }(<30 \% \\
\text { UPDRS motor improvement), responding }(30 \%-70 \% \text { motor improvement) and optimally } \\
\text { responding }(>70 \% \text { motor improvement) contralateral body-sides to the medial STN } \\
\text { border and midcommissural point. } \\
{ }^{*} \text { Differences found in dorsoventral plane between non-responding and optimally } \\
\text { responding }(P=0.03) \text { and responding and optimally responding body-sides }(P<0.01) \text { were } \\
\text { statistically significant. } \\
\text { STN, subthalamic nucleus; UPDRS, Unified Parkinson's Disease Rating Scale. }\end{array}$} \\
\hline
\end{tabular}

Mean stereotactic distances from centres of stimulation of non-responding, responding and optimally responding contralateral body-sides to both the medial STN border and MCP are mentioned in table 1.

The theoretic DBS hotspots were defined at $2.8 \mathrm{~mm}$ lateral, $1.7 \mathrm{~mm}$ anterior, $2.5 \mathrm{~mm}$ superior relative to medial STN border, and at $12.3 \mathrm{~mm}$ lateral, $1.6 \mathrm{~mm}$ posterior and $2.3 \mathrm{~mm}$ inferior relative to MCP. The Euclidean distance from the centres of stimulation to the hotspot defined relative to the medial STN border differed significantly between non-responding and responding body-sides $(\mathrm{P}=0.01)$ and between non-responding and optimally responding body-sides $(\mathrm{P}<0.01)$ (figure $3 \mathrm{~A})$. No differences were found for Euclidean distance from the centres of stimulation to the theoretic hotspot defined relative to MCP (figure 3B).

A significant negative correlation was found (Pearson's correlation -0.52, $\mathrm{P}<0.01$ ) between individual percentage UPDRS improvement and Euclidean distance from the centre of stimulation to the theoretic DBS hotspot defined relative to the medial STN border (figure 4A). A similar negative correlation was found when the optimally responding body-sides were excluded from analysis (Pearson's correlation $-0.49, \mathrm{P}<0.01$ ). No correlation was found between individual percentage UPDRS improvement and Euclidean distance from the centre of stimulation to the theoretic DBS hotspot defined relative to MCP (figure 4B).

\section{DISCUSSION}

\section{Medial STN border as reference point compared with MCP}

We compared MCP and medial STN border as reference for evaluation of the relationship between DBS location and motor improvement in patients with PD. In accordance with other studies, we did not find correlation when MCP was chosen as reference. ${ }^{9131718}$ However, with the medial STN border as reference we were able to define a theoretic optimal location for stimulation, at $2.8 \mathrm{~mm}$ lateral, $1.7 \mathrm{~mm}$ anterior and $2.5 \mathrm{~mm}$ superior to the intersection of Bejjani's line with the medial border of the STN. Increasing Euclidean distance from the centres of stimulation to this 'hotspot' showed a significant negative correlation with motor improvement.

The similar baseline levodopa responses for non-responding, responding and optimally responding body-sides strongly suggests that the observed variability in clinical outcome was not caused by patient selection. Furthermore, the stimulation parameters and proximity of the active contact points relative to the electrophysiological dorsal STN border did not differ between the three groups, suggesting that the observed variability in outcome can neither be explained by differences in stimulation settings or too ventrally applied stimulation: in all groups 

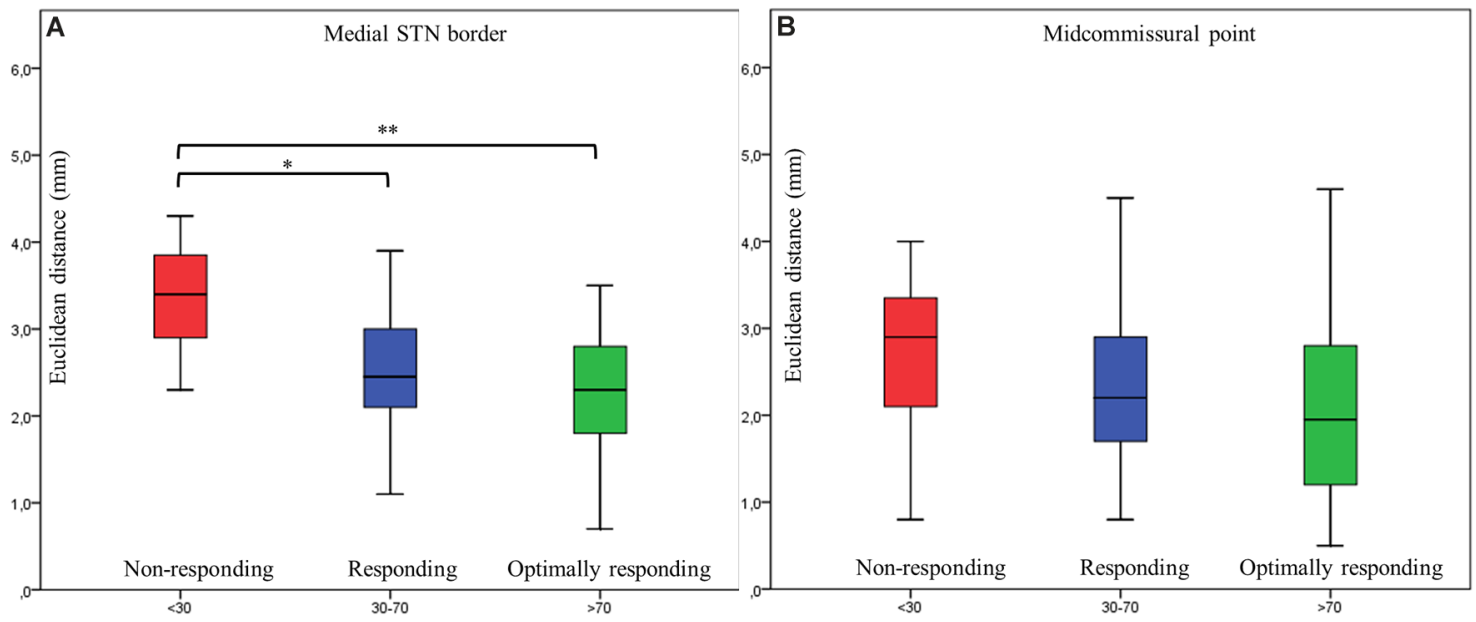

Figure 3 (A) Euclidean distance from centres of stimulation of non-responding (<30\% Unified Parkinson's Disease Rating Scale motor improvement after 12 months, red box plot), responding (30\%-70\% improvement, blue box plot) and optimally responding (>70\% improvement, green box plot) contralateral body-sides to theoretic optimal deep brain stimulation location ('hotspot') defined relative to medial subthalamic nucleus (STN) border (ie, $2.8 \mathrm{~mm}$ lateral, $1.7 \mathrm{~mm}$ anterior, $2.5 \mathrm{~mm}$ superior). Average Euclidean distance differed significantly between non-responding and responding body-sides ( $\mathrm{P}=0.01^{*}$ ) and between non-responding and optimally responding body-sides $\left(P \leq 0.01^{* *}\right)$. (B) Euclidean distance from centres of stimulation of non-responding, responding and optimally responding body-sides to theoretic hotspot defined relative to midcommissural point (MCP) (ie, 12.3 lateral, 1.6 posterior, 2.3 inferior). Average Euclidean distances did not differ between groups.

active stimulation was applied in dorsal regions of the STN, but active contacts of non-responding body-sides were too far off the motor hotspot within the dorsolateral STN.

This study is the first to define such a hotspot on MRI. The medial STN border as reference point to locate the dorsolateral sensorimotor part of STN thus was less subjected to anatomical variation than MCP and therefore offered superior insight in anatomical location of electrode contact. Indeed, we found high variance in location in all three stereotactic directions of medial STN border relative to MCP in the current study. Identification of this new reference point is well feasible at $1.5 \mathrm{~T}$ MRI and therefore readily applicable for all DBS teams.

\section{Optimal DBS location within STN}

The dorsolateral part of the STN is traditionally considered to represent the motor area and optimal location for stimulation. ${ }^{19}$ Thus far, this part could only be identified by intraoperative electrophysiological findings, showing increased beta oscillatory activity. ${ }^{20}$ Although some studies showed most active contacts to be in or near the dorsolateral STN on MRI, a significant correlation with motor improvement was never found. ${ }^{18} 21$ Defining an optimal DBS location within the STN is highly desirable as it could result in more understanding of response rate to DBS and how this varies as a function of electrode location. Active contact localisation in non-responders could be evaluated and,

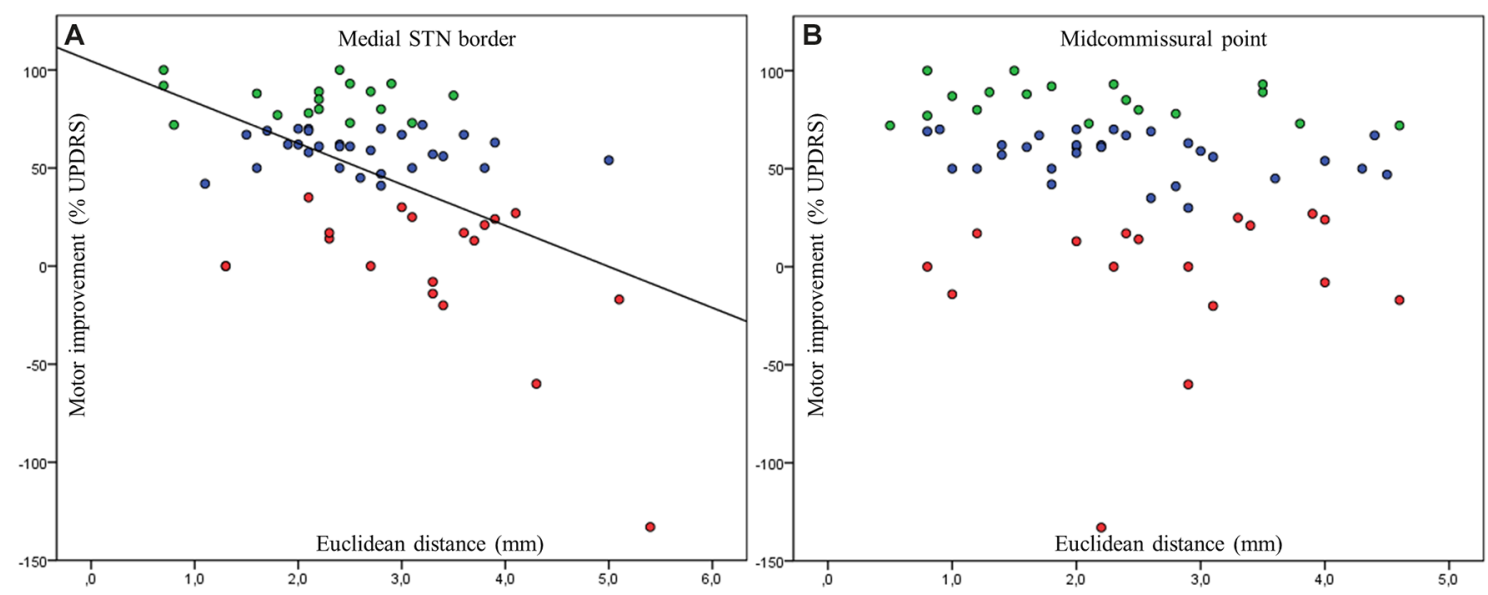

Figure 4 (A) Significant negative correlation (Pearson's correlation -0.52) between percentage Unified Parkinson's Disease Rating Scale (UPDRS) improvement after 12 months and Euclidean distance from centre of stimulation of individual body-sides to theoretic optimal deep brain stimulation location ('hotspot') defined relative to medial subthalamic nucleus (STN) border (ie, $2.8 \mathrm{~mm}$ lateral, $1.7 \mathrm{~mm}$ anterior, $2.5 \mathrm{~mm}$ superior). Green dots represent optimally responding (>70\% UPDRS improvement), blue dots responding (30\%-70\% UPDRS improvement) and red dots non-responding (<30\% UPDRS improvement) body-sides. (B) Absence of significant correlation between percentage UPDRS improvement after 12 months and Euclidean distance from centre of stimulation of individual body-sides to theoretic hotspot defined relative to midcommissural point (MCP) (ie, 12.3 lateral, 1.6 posterior, 2.3 inferior). 


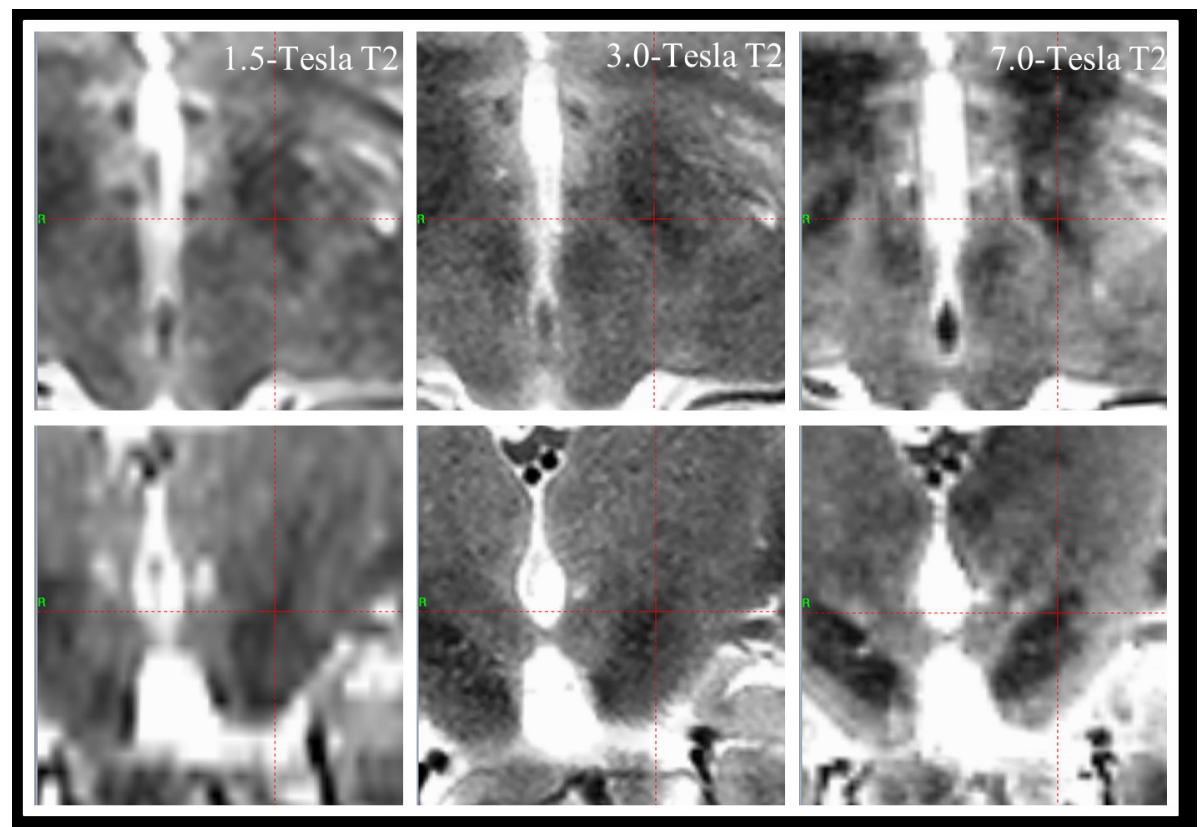

Figure 5 Axial and coronal midbrain sections showing optimal deep brain stimulation (DBS) location ('hotspot') within the subthalamic nucleus (STN) on three different MRI field -strenghts. Left upper and lower panel, a 1.5 T T2 sequence; middle upper and lower panel, a 3.0 T T2 sequence and right upper and lower panel, a 7.0 T T2 sequence. All upper panels are axial orientated and all lower panels are coronal orientated sections. The hypointense STN signal is situated anterolateral to the (most upper part of the) red nucleus on axial orientated sections and visible as hypointense almond shaped above substantia nigra on coronal orientated sections. The cross-section of the two dotted red lines coincides with the defined optimal DBS location with medial STN border as reference (ie, $2.8 \mathrm{~mm}$ lateral, $1.7 \mathrm{~mm}$ anterior, $2.5 \mathrm{~mm}$ superior). This hotspot is situated in the dorsolateral sensorimotor part of the nucleus. Every increase in field strength results in clearer STN delineation so that the optimal stimulation area can best be evaluated on 7.0 T T2 MRI.

if possible, stimulation could be shifted to a contact that is more in the vicinity of this hotspot. During the planning phase in de novo patients, the hotspot could be visualised on preoperative stereotactic imaging, thereby assuring electrode placement within this area. In this way, optimal and thus less variable motor improvement for individual patients may be obtained. In theory, a preoperatively identifiable optimal DBS location on MRI could make MER and test stimulation in awake patients redundant, allowing DBS surgery to be performed under general anaesthesia. Such approach would offer a major advantage in terms of patient comfort.

\section{Study limitations}

The current study has several limitations. First, 1.5 T T2 MRI was used for STN identification, as stated this field strength is sufficient for medial STN border identification. However, it is less well suited for precise evaluation of dorsolateral STN location. Due to these image quality limitations of $1.5 \mathrm{~T}$ MRI, exact inter-relationship of contact localisation and dorsolateral STN was suboptimal. Recently, we started using both axial and coronal 3.0 T and three-dimensional 7.0 T T2-weighted MRI. Especially 7.0 T provides superior representation of the STN in axial and coronal planes, thereby delineating the dorsolateral sensorimotor part/theoretic hotspot (figure 5). Second, tractography possibly could provide more insight in stimulation of STN subregions. ${ }^{22}$ Third, the defined hotspot within the STN was based on the location of active contact points of 17 optimally responding contralateral body-sides and represents average numbers. These coordinate points indicate an area within the STN rather than a specific point in stereotactic space and should be interpreted together with patient-specific T2-weighted MRI findings. Future studies incorporating the theoretic hotspot during preoperative stereotactic planning in de novo patients are needed to evaluate the value of this presumed optimal location in a prospective manner. Fourth, because of our methods evaluating left-sided and right-sided motor scores separately, we were not able to relate stimulation location to improvement of axial motor symptoms, which are known debilitating symptoms in patients with advanced PD. ${ }^{23}$

\section{CONCLUSION}

While studies employing MCP as anatomical reference failed to show correlation between DBS location and motor improvement following STN DBS, the current study employed the medial border of the STN as reference and provided good insight in optimal location of DBS. It allowed defining a DBS hotspot at $2.8 \mathrm{~mm}$ lateral, $1.7 \mathrm{~mm}$ anterior and $2.5 \mathrm{~mm}$ superior relative to medial STN border. Increasing Euclidean distance from the centre of stimulation to this area showed a significant negative correlation with motor improvement. We therefore propose the medial STN border as a better individual reference point than the currently used MCP on preoperative stereotactic imaging, in order to obtain optimal and thus less variable motor improvement for individual patient with PD undergoing STN DBS.

Contributors $\mathrm{MB}$, conception of the work, data collection, data analysis and interpretation, drafting the article, critical revision of the article, final approval of the version to be published. PRS, conception of the work, critical revision of the article, final approval of the version to be published. VJJO, critical revision of the article, data collection, final approval of the version to be published. RV, conception of the work, critical revision of the article, final approval of the version to be published. FMC, critical revision of the article, final approval of the version to be published. RMADB, critical revision of the article, final approval of the version to be published. PvdM, conception of the work, drafting the article, critical revision of the article, final approval of the version to be published.

Disclaimer The DBS team of the AMC received unrestricted research grants from Medtronic and received financial compensation for teaching courses for 
the European Continue Medical Training (ECMT) programme. The DBS team of the Haga Teaching Hospital/LUMC received compensation for DBS training activities from Medtronic. MB received travel grants from Medtronic. PRS acts as independent advisor for Boston Scientific, Elekta, Medtronic and Sapiens Steering Brain Stimulation. FMC received speaking fees from AbbVie, ECMT and Medtronic, received travel support from Boston Scientific, acts as an independent advisor for Boston Scientific and Medtronic. VJJO, RV, RMADB and PvdM have no disclosures.

\section{Competing interests None declared.}

Ethics approval Patients were selected from a multicentre randomised controlled study on the effectiveness of STN versus globus pallidus internus DBS that included patients between February 2007 and March 2011. Medical ethics committee of Academic Medical Center Amsterdam approved the study and patients provided written informed consent.

Provenance and peer review Not commissioned; externally peer reviewed.

(c) Article author(s) (or their employer(s) unless otherwise stated in the text of the article) 2018. All rights reserved. No commercial use is permitted unless otherwise expressly granted.

\section{REFERENCES}

1 Rodriguez-Oroz MC, Obeso JA, Lang AE, et al. Bilateral deep brain stimulation in Parkinson's disease: a multicentre study with 4 years follow-up. Brain 2005; 128:2240-9.

2 Moro E, Lozano AM, Pollak P, et al. Long-term results of a multicenter study on subthalamic and pallidal stimulation in Parkinson's disease. Mov Disord 2010;25:578-86.

3 Krack P, Batir A, Van Blercom N, et al. Five-year follow-up of bilateral stimulation of the subthalamic nucleus in advanced parkinson's disease. N Eng/ J Med 2003;349:1925-34

4 Obeso JA, Olanow CW, Rodriguez-Oroz MC, et al. Deep-brain stimulation of the subthalamic nucleus or the pars interna of the globus pallidus in parkinson's disease. N Engl J Med 2001;345:956-63.

5 Aviles-Olmos I, Kefalopoulou Z, Tripoliti E, et al. Long-term outcome of subthalamic nucleus deep brain stimulation for Parkinson's disease using an MRI-guided and MRIverified approach. J Neurol Neurosurg Psychiatry 2014;85:1419-25.

6 Odekerken VJ, van Laar T, Staal MJ, et al. Subthalamic nucleus versus globus pallidus bilateral deep brain stimulation for advanced Parkinson's disease (NSTAPS study): a randomised controlled trial. Lancet Neurol 2013;12:37-44.

7 McClelland S, Ford B, Senatus PB, et al. Subthalamic stimulation for Parkinson disease: determination of electrode location necessary for clinical efficacy. Neurosurg Focus 2005:19:1-9.

8 Daniluk S, G Davies K, Ellias SA, et al. Assessment of the variability in the anatomical position and size of the subthalamic nucleus among patients with advanced Parkinson's disease using magnetic resonance imaging. Acta Neurochir 2010;152:201-10.

9 Nestor KA, Jones JD, Butson CR, et al. Coordinate-based lead location does not predict Parkinson's disease deep brain stimulation outcome. PLoS One 2014;9:e93524.

10 Paek SH, Han JH, Lee JY, et al. Electrode position determined by fused images of preoperative and postoperative magnetic resonance imaging and surgical outcome after subthalamic nucleus deep brain stimulation. Neurosurgery 2008;63:925-37.

11 Andrade-Souza YM, Schwalb JM, Hamani C, et al. Comparison of three methods of targeting the subthalamic nucleus for chronic stimulation in Parkinson's disease. Neurosurgery 2005;56:360-8.

12 Wodarg F, Herzog J, Reese R, et al. Stimulation site within the MRI-defined STN predicts postoperative motor outcome. Mov Disord 2012;27:874-9.

13 Kasasbeh A, Abulseoud OA, Matsumoto JY, et al. Lack of differential motor outcome with subthalamic nucleus region stimulation in parkinson's disease. J Clin Neurosci 2013;20:1520-6.

14 Caire F, Ranoux D, Guehl D, et al. A systematic review of studies on anatomical position of electrode contacts used for chronic subthalamic stimulation in parkinson's disease. Acta Neurochir 2013;155.

15 Bejjani BP, Dormont D, Pidoux B, et al. Bilateral subthalamic stimulation for parkinson's disease by using three-dimensional stereotactic magnetic resonance imaging and electrophysiological guidance. J Neurosurg 2000;92:615-25.

16 Martínez-Martín P, Gil-Nagel A, Gracia LM, et al. Unified parkinson's disease rating scale characteristics and structure. The cooperative multicentric group. Mov Disord 1994; 9:76-83

17 McClelland S, Ford B, Senatus PB, et al. Typical variations of subthalamic electrode location do not predict limb motor function improvement in Parkinson's disease. J Clin Neurosci 2009:16(6):771-8.

18 Weise LM, Seifried C, Eibach S, et al. Correlation of active contact positions with the electrophysiological and anatomical subdivisions of the subthalamic nucleus in deep brain stimulation. Stereotact Funct Neurosurg 2013;91:298-305.

19 Zaidel A, Spivak A, Grieb B, et al. Subthalamic span of beta oscillations predicts deep brain stimulation efficacy for patients with parkinson's disease. Brain 2010;133:2007-21.

20 Gross RE, Krack P, Rodriguez-Oroz MC, et al. Electrophysiological mapping for the implantation of deep brain stimulators for parkinson's disease and tremor. Mov Disord 2006;21(S14):259-283.

21 Godinho F, Thobois S, Magnin M, et al. Subthalamic nucleus stimulation in Parkinson's disease : anatomical and electrophysiological localization of active contacts. J Neurol 2006;253:1347-55.

22 Lambert C, Zrinzo L, Nagy Z, et al. Confirmation of functional zones within the human subthalamic nucleus: patterns of connectivity and sub-parcellation using diffusion weighted imaging. Neuroimage 2012;60:83-94.

23 Fasano A, Aquino CC, Krauss JK, et al. Axial disability and deep brain stimulation in patients with parkinson disease. Nat Rev Neurol 2015;11:98-110. 


\section{JNNP}

Deep brain stimulation for Parkinson's disease: defining the optimal location within the subthalamic nucleus

Maarten Bot, P Richard Schuurman, Vincent J J Odekerken, Rens

Verhagen, Fiorella Maria Contarino, Rob M A De Bie and Pepijn van den Munckhof

J Neurol Neurosurg Psychiatry published online January 20, 2018

Updated information and services can be found at:

http://jnnp.bmj.com/content/early/2018/01/20/jnnp-2017-316907

\section{These include:}

References This article cites 22 articles, 1 of which you can access for free at: http://jnnp.bmj.com/content/early/2018/01/20/jnnp-2017-316907\#ref-li st-1

Email alerting

Receive free email alerts when new articles cite this article. Sign up in the service box at the top right corner of the online article.

\section{Notes}

To request permissions go to:

http://group.bmj.com/group/rights-licensing/permissions

To order reprints go to:

http://journals.bmj.com/cgi/reprintform

To subscribe to BMJ go to:

http://group.bmj.com/subscribe/ 